\title{
Utilization of brown rice powder on the nutritional composition, cooking characteristics and sensory properties of beef patties
}

\author{
Mousavi, L., Nur Farhana, S.M.Z. and *Wan Rosli, W.I. \\ Nutrition and Dietetics Program, School of Health Sciences, Universiti Sains Malaysia Health Campus, 16150 Kubang \\ Kerian, Kelantan, Malaysia
}

\section{Article history: \\ Received: 10 April 2019 \\ Received in revised form: 15 \\ May 2019 \\ Accepted: 16 May 2019 \\ Available Online: 22 May \\ 2019}

\section{Keywords:}

Brown Rice,

Beef patties,

Sensory evaluation,

Nutritional composition

\section{DOI:}

https://doi.org/10.26656/fr.2017.3(6).153

\begin{abstract}
Beef patties are the most popular fast food worldwide, including Malaysia. As long as a beef patty is one of the Malaysians' favorite western dishes and can be easily found in the high-end western restaurant, so far assessment of the nutrient composition, cooking characteristics and sensory properties of that was important for healthcare aspect. In the current study, the nutritional values of beef patties incorporated with various level of brown rice powder (BRP) $(2 \%, 4 \%$ and, $6 \%)$ were evaluated. The result of protein content in raw and cooked beef patties incorporated with $6 \%$ of BRP demonstrated the highest percentage (17.41\% and $17.48 \%$, consequently). Further finding displayed that the lowest fat concentration was recorded in the formulation of $6 \%$ BRP and 4\% BRP raw and cooked beef patties (12.44\% and $11.45 \%)$ frequently. On the other hands, the results of moisture content of $4 \%$ BRP raw beef patties and $6 \%$ BRP cooked beef patty demonstrate that the lowest percentage $(61.16 \%$ and $54.92 \%)$ while the carbohydrate concentration recorded the highest percentage in both formulations. In additional, beef patty formulated with $6 \%$, BRP showed the lowest diameter reduction at $13.33 \%$ compared to other treatment. The calorie content of cooked beef patty and cooking yield of all formulations were recorded in the range of $584 \mathrm{kcal} / 100 \mathrm{~g}$ to $594 \mathrm{kcal} / 100 \mathrm{~g}$ and $78.09 \%$ to $80.48 \%$ accordingly. However, $2 \%$ BRP incorporation in beef patty did not change the sensory properties and consumer acceptability of BRP-based beef patties. In conclusion, beef patty formulation of more than $4 \%$ BRP in beef patties was effective in improving protein, ash, carbohydrate content and percentage of diameter reduction while reducing fat content.
\end{abstract}

\section{Introduction}

Currently, meat consumption in developing countries has been continuously increasing. According to FAO, (2007) from a modest average annual per capita consumption of $10 \mathrm{~kg}$ in the $1960 \mathrm{~s}, 26 \mathrm{~kg}$ in 2000 and will reach $37 \mathrm{~kg}$ around the year 2030 (Joint FAO/WHO Expert Committee on Food Additives, 2007). The fast progression of urbanization and tendency among city dwellers to spend more on food influence the rising demand for meat in developing countries. The greater demand for meat has led to intensive livestock production systems. There are some challenges for animal health management and meat processing procedure to make an intensive production system. The producer must manage the plan and level of biosecurity that will effective in preventing disease and also have to reduce stress to the animals as far as possible in order to have quality meat. On the other hands, demand and processing of meat have been playing a prominent role between consumers. Nowadays, one of the meats processing that has high demand all over the world is meat patties. Some of the reasons are their longer shelf life, readily available in different taste and affordable cost. Patties are usually in a disc-like shape that formed from minced meat mix by different ingredient which is its common commercial name is burgers or hamburgers (Joint FAO/WHO Expert Committee on Food Additives, 2007) Originally, patties were made from beef but in recent years chicken have become common patties as popular as beef patties in Malaysia and other parts of the world. Usually, the patties are served and consumed in warm to medium hot mode. Therefore, heat treatment (pan-frying) is commonly applied to make the products palatable. In current years, researchers trying to make a healthier with high nutritional values beef patty product by replacing different valuable ingredients to make a beef patty. Since the rice is widely cultivated in Asia and over 100 countries including Malaysia and it is a staple food for the majority of people in the world (Musa et al., 2011), several studies have been reported on the different 
varieties of rice. In the latest research, researcher have been shown that it is better to consume unpolished (brown) rice rather than white rice due to the presence of outer bran layer nutritional components such as dietary fibres, phytic acid, vitamins E, B and $\gamma$-aminobutyric acid (GABA) compared to the white rice (WR) (Babu et al., 2009; Alice and Wan Rosli, 2015). Besides that, the brown layer has been reported to have therapeutic effects like hypercholesterolemia, improvement of low-density lipoprotein (LDL), cholesterol level and preventing type II diabetes mellitus (T2DM) (Hammond, 1994; Dadkhah el al., 2012) because of its bioactive constituents. Despite the fact that brown rice is more nutritious than white rice, its consumption is not widespread because consumers are less favoured due to its taste, colour, price, tradition, brand preference, dietary habits and availability (Zhang et al., 2010). Notwithstanding, the change of staple food from polished rice to brown is expected to maintain and promote the healthy life and improve the quality of life (Alice and Wan Rosli, 2015). However, there are limited researches to show the potential of BRP in food products. Therefore, the aim of this study is to investigate the effect of partial replacement of potato starch with BRP on nutritional composition, physicochemical properties and sensorial characteristics of beef patties and to develop low-fat meat patties with high fibre and protein content by the formulation of different percentage of brown rice.

\section{Materials and methods}

\subsection{Sample preparation brown rice powder (BRP)}

Table 1. Beef patties formulated with different levels of BRP.

\begin{tabular}{lcccc}
\hline \multirow{2}{*}{ Ingredients BRP Levels } & \multicolumn{4}{c}{ Quantities } \\
\cline { 2 - 5 } & $\begin{array}{c}\text { Control } \\
(0 \%)\end{array}$ & $2 \%$ & $4 \%$ & $6 \%$ \\
\hline Beef (hind quarter) & 54 & 54 & 54 & 54 \\
Fat & 11 & 11 & 11 & 11 \\
Water & 23 & 23 & 23 & 23 \\
Potato starch & 6 & 4 & 2 & 0 \\
Brown rice powder (BRP) & 0 & 2 & 4 & 6 \\
Isolated soy protein & 4 & 4 & 4 & 4 \\
Salt & 1 & 1 & 1 & 1 \\
Spices and seasoning & 1 & 1 & 1 & 1 \\
\hline Total & 100 & 100 & 100 & 100 \\
\hline
\end{tabular}

A total of one $\mathrm{kg}$ of brown rice was purchased from Kota Bharu, Kelantan, Malaysia. Then, rice was ground into powder form by using electrical grinder (National brand, MX-895M model) and after that was sifted by using a $15 \mathrm{~cm}$ round stainless steel flour sieve (Rosli et al., 2011). Following that, four beef patty formulations ( $0 \%$ (control), $2 \%, 4 \%$ and $6 \%$ of brown rice powder replacing with potato starch) with the same percentage of the ingredient were prepared (Table 1). Samples were stored in a freezer at $-18^{\circ} \mathrm{C}$ until further analysis (Rosli et al., 2011).

\subsection{Beef patty processing}

Isolated soy protein was blended with $13 \%$ of water and fat manually. The emulsion prepared (called preemulsion) was stored in a chiller $\left(2-5^{\circ} \mathrm{C}\right)$ until ready for use. Beef cut of the hindquarter beef was cut manually and minced through a $4 \mathrm{~mm}$-diameter grinder plate. Salt was added to the minced beef and mixing was carried out using a Hobart mixer (N-50 Canada) (3 mins). Water $(10 \%)$ mixed with spices and potato starch was added into the mixer and mixed ( 2 mins). Following that, the pre-emulsion was added and mixing (2 mins). The finished meat batter was weighed into $70 \mathrm{~g}$ portion, and then manually stamps to produce a uniform beef patty. The raw beef patties were frozen at $-18^{\circ} \mathrm{C}$. All the procedures above were repeated and part of the potato starch (PS) was substituted with BRP at the levels of $0 \%$ (0BRP:6PS), 2\% (2BRP:4PS), 4\% (4BRP:2PS) and 6\% (6BRP: 0PS).

\subsection{Cooking procedure}

Beef patties were thaw at $4^{\circ} \mathrm{C}$ for $12 \mathrm{hrs}$. Beef patty samples were cooked in a pan-fried electric skillet (Model KX-11K1, Sharp Corporation, Japan) for 7 to 8 mins until an internal temperature of $72 \pm 1^{\circ} \mathrm{C}$ was achieved.

\subsection{Analysis of nutritional composition}

Both raw and cooked samples were analysed for proximate compositions by using the method of Association of Official Analytical Chemists (AOAC 1996).

\subsection{Cooking yield analysis}

Cooking yield of beef patties was determined by measuring the weight of three patties for each treatment/ batch including control and calculating weight differences for patties before and after cooking, as follows (El-Magoli et al., 1996):

$$
\text { Cooking yield }(\%)=\frac{(\text { cooked weight } \times 100)}{\text { Raw weight }}
$$

\subsection{Moisture and fat retention}

The moisture and fat retention values represent the amount of moisture and fat retained in the cooked product per $100 \mathrm{~g}$ of raw sample. These values were calculated according to the following equations (ElMagoli et al., 1996):

$$
\begin{aligned}
& \text { Moisture retention }(\%)=\frac{(\text { percent yield } \times \% \text { moisture in cooked patties })}{100} \\
& \text { Fat retention }(\%)=\frac{(\text { cooked weight } \times \% \text { fat in cooked beef patties })}{\text { (raw weight } \times \% \text { fat in raw beef patties })} \times 100
\end{aligned}
$$




\subsection{Diameter reduction}

Diameter reduction is measured to know the shrinkage of the cooked patties. Measurements for diameter reduction were determined using the following equation (Rosli et al., 2011):

Diameter reduction $(\%)=\frac{\text { raw beef patties diameter-cooked beef patties diameter }}{\text { raw beef patties diameter }} \times 100$

\subsection{Sensory evaluation}

Sensory evaluation was carried out by 60 untrained panellists. All panellists evaluated samples for the scale attributes such as appearance, texture, juiciness, flavour and overall acceptance on a 7 -point scale $(0=$ dislike extremely until, 7 = like extremely) (Rosli et al., 2011).

\subsection{Data analysis}

Data obtained tested for significance using ANOVA and Duncan Multiple Range Test using SPSS version 22.0. All the measurements are carried out in triplicates $(\mathrm{n}=3)$, aspect for sensory evaluation. The significant level is $\mathrm{p} \leq 0.05$ (Rosli et al., 2011).

\section{Results}

\subsection{Nutritional composition of raw beef patties}

Figure 4 provided reveals a number of clear differences between the major concentrations of the nutritional composition in raw beef patties formulated with different percentage of BRP replacing with starch (Figure 1). The result indicated that the highest percentage of BRP $(6 \%)$ replacing with starch in formulation showed that significantly $(\mathrm{p}<0.05)$ increase in the level of protein content (17.41\%) while the lowest (2\%) BRP formulation showed the lowest protein concentration (15.91\%). However, one particularly interesting fact highlighted by the result of protein concentration $(16.26 \%)$ of the mid amount of BRP $(4 \%)$ formulation without any significant different $(p>0.05)$. The result of fat percentage in all formulations demonstrated in the range of $12.44 \%$ to $13.82 \%$. From the results, it was clear that raw beef added with the highest amount of BRP (6\%) showed significant difference $(p<0.05)$ with the lowest percentage of fat. Fat percentage of control raw beef patty $(12.77 \%)$ was found to be slightly higher compared to $6 \%$ BRP raw beef patty, but no significant difference $(\mathrm{p}>0.05)$. Meanwhile, raw beef patty formulation with $2 \%$ and $4 \%$ of BRP displayed significantly $(p<0.05)$ higher fat content $(13.82 \%$ and $12.92 \%$, respectively) compared to the control. From the result, it was also important to note that the lowest BRP (2\%) beef patty formulation in raw beef patty showed that the highest concentration $(13.82 \%)$. The data of ash content showed rang of the highest and lowest concentrations of ash (3.85 - 4.56\%) with $6 \%$ and $2 \%$ of BRP formulation in raw beef patty consequently. However, the result of ash content did not show any significant difference with each other $(p<0.05)$. The result displayed that increment of BRP levels had been shown significantly increase $(p<0.05)$ the moisture content of raw beef patty ranged from $61.18 \%$ to $64.03 \%$. Nevertheless, control raw beef patty significantly $(p<0.05)$ recorded the highest moisture content $(65.05 \%)$. The total carbohydrates content of raw beef patty formulations with BRP showed a decrease (1.56-5.32\%), with increasing levels of BRP. In addition, carbohydrates content of control raw beef patty (2.33\%) was slightly lower compared with $2 \%$ BRP raw beef patty (3.51\%), but not significant different ( $p>0.05)$. On the other hand, the caloric value of raw beef patty increased directly while the levels of BRP had been increased. The result indicated that increment of BRP levels had been shown significantly increase $(p<0.05)$ the calorie content of raw beef patty ranged from 577 $\mathrm{kcal} / 100 \mathrm{~g}$ to $601 \mathrm{kcal} / 100 \mathrm{~g}$. However, for control raw beef patty $(576 \mathrm{kcal} / 100 \mathrm{~g})$ and 2\% BRP raw beef patty $(577 \mathrm{kcal} / 100 \mathrm{~g})$, their calorie content was significantly $(p<0.05)$ lower compared to $6 \%$ BRP raw beef patty.

\subsection{Nutritional composition of cooked beef patties}

Figure 5 indicated that the chemical composition of cooked beef patty formulated with a different formulation of brown rice powder (BRP) (Figure 2). The lowest and highest percentage of protein in cooked beef patties formulated (6\% and 4\%) ranged from $16.87 \%$ to $17.48 \%$ consequently. The protein content of $2 \%$ BRP cooked beef patty $(17.18 \%)$ was found to be slightly lower compared with 6\% BRP cooked beef patty, however, did not show a significant difference $(\mathrm{p}>0.05)$. The control and 4\% BRP cooked beef patties displayed the lower values in protein concentration, $(16.87 \%$ and $16.99 \%$ ) respectively compared with $6 \%$ BRP cooked beef patty. However, the difference was not significant ( $p>0.05)$. The result of fat content demonstrated that only $2 \%$ BRP formulation of beef patty displayed the highest amount of fat concentration (12.64\%) with significant difference $(p<0.05)$. The result of fat content in control patty and other formulations of beef patty did not show any significant difference $(p>0.05)$. The cooked beef patty formulated with $4 \%$ BRP sowed the highest concentration of ash content $(4.56 \%)$ with significant difference $(\mathrm{p}<0.05)$ followed by $6 \%$ BRP cooked beef patty (4.28). However, the ash content of control cooked beef patty and 2\% BRP cooked beef patty were significantly $(\mathrm{p}<0.05)$ lower compared with $6 \%$ BRP raw beef patty. Moisture content in cooked beef patties decreased inversely with increased the level of BRP. However, the moisture content of cooked beef patties formulated with $2 \%, 4 \%$ and $6 \%$ BRP showed the 


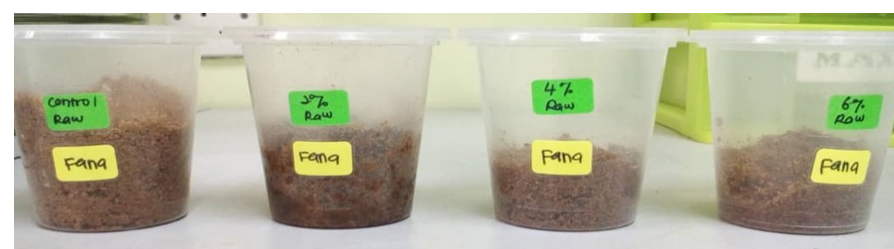

Figure 1. Dried raw beef patty for nutrition composition analyses

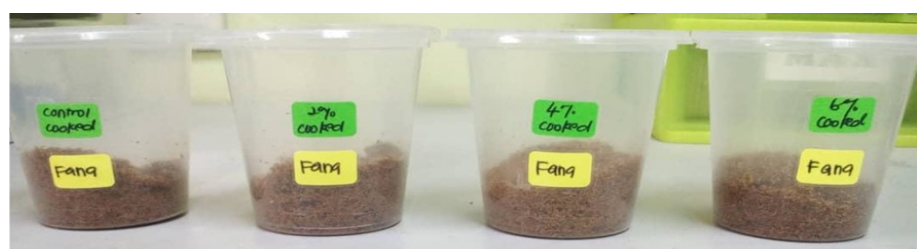

Figure 2. Dried cooked beef patty for nutrition composition analyses
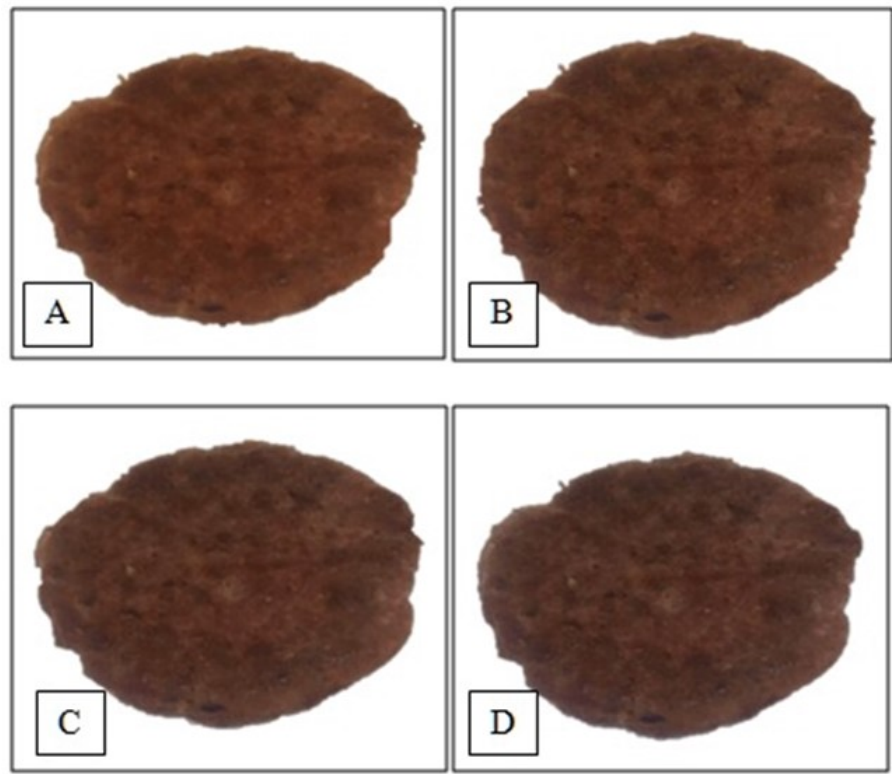

Figure 3. Pictures of cooked beef patties with levels of BRP formulations, A: Cooked beef patty without BRP (control), B: Cooked beef patty with $2 \%$ BRP, C: Cooked beef patty with $4 \%$ BRP, D: Cooked beef patty with $6 \%$ BRP.

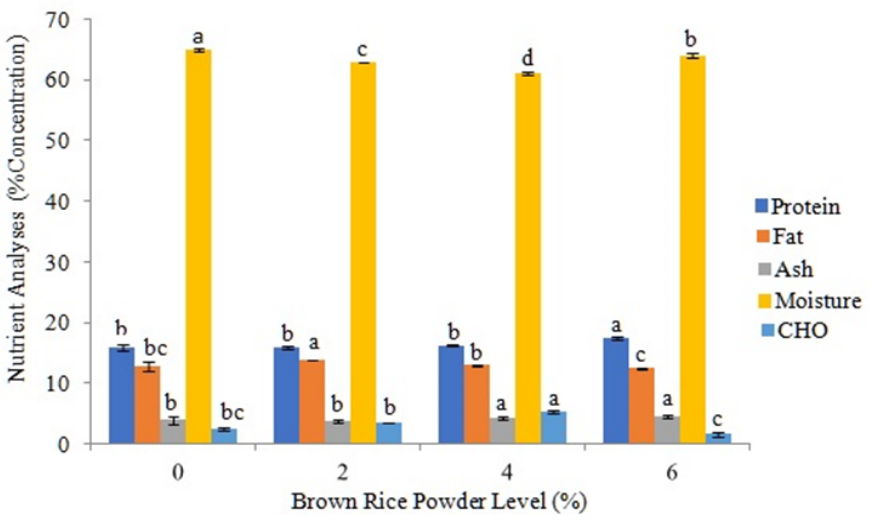

Figure 4. Nutrient analyses of raw beef patty incorporated with BRP. BRP \% level: Calorie (kcal/100 g): 0: $576 \pm 1.73^{\mathrm{c}} ; 2$ : $577 \pm 8.66^{\mathrm{c}} ; 4: 592 \pm 1.00^{\mathrm{b}} ; 6: 601 \pm 2.31^{\mathrm{a}}$.

${ }^{\mathrm{a}-\mathrm{d}}$ Mean values within the same row bearing different superscripts differ significantly $(\mathrm{P}<0.05)$.

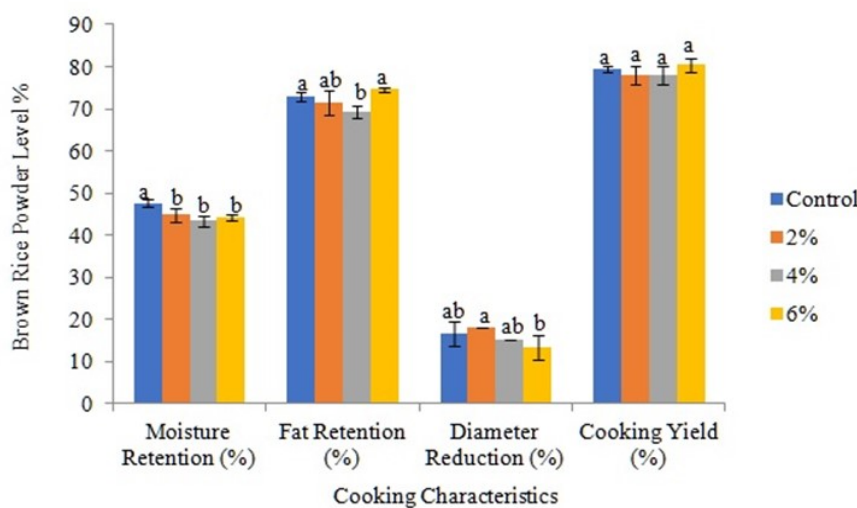

Figure 5. Nutrient analyses of cooked beef patty incorporated with BRP. BRP \% level: Calorie (kcal/100 g): 0: $592 \pm 1.53^{\mathrm{a}}$; 2: $588 \pm 12.29^{\mathrm{a}} ; 4: 584 \pm 2.31^{\mathrm{a}} ; 6: 594 \pm 5.29^{\mathrm{a}}$.

${ }^{\mathrm{a}-\mathrm{c}}$ Mean values within the same row bearing different superscripts differ significantly $(\mathrm{p}<0.05)$.

Table 2. Sensory attributes of cooked beef patties added with BRP $(\mathrm{N}=60)$.

\begin{tabular}{lcccc}
\hline \multirow{2}{*}{ Sensory Attribute } & \multicolumn{4}{c}{ BRP Content } \\
\cline { 2 - 5 } & $0 \%$ & $2 \%$ & $4 \%$ & $6 \%$ \\
\hline Colour & $4.98 \pm 1.24^{\mathrm{a}}$ & $4.98 \pm 1.19^{\mathrm{a}}$ & $4.60 \pm 1.11^{\mathrm{ab}}$ & $4.43 \pm 1.45^{\mathrm{b}}$ \\
Texture & $4.92 \pm 1.31^{\mathrm{a}}$ & $4.78 \pm 1.24^{\mathrm{a}}$ & $4.57 \pm 1.41^{\mathrm{a}}$ & $3.95 \pm 1.58^{\mathrm{b}}$ \\
Juiciness & $5.17 \pm 1.14^{\mathrm{a}}$ & $4.63 \pm 1.18^{\mathrm{b}}$ & $3.82 \pm 1.28^{\mathrm{c}}$ & $3.50 \pm 1.35^{\mathrm{c}}$ \\
Flavor & $5.23 \pm 1.14^{\mathrm{a}}$ & $4.75 \pm 1.31^{\mathrm{ab}}$ & $4.37 \pm 1.48^{\mathrm{bc}}$ & $4.23 \pm 1.48^{\mathrm{c}}$ \\
Overall Acceptance & $5.25 \pm 1.10^{\mathrm{a}}$ & $5.03 \pm 1.09^{\mathrm{a}}$ & $4.38 \pm 1.24^{\mathrm{b}}$ & $4.13 \pm 1.44^{\mathrm{b}}$ \\
\hline
\end{tabular}


highest to lowest moisture content $(57.40 \%, 55.54 \%$ and $54.92 \%$ ) in descending order, respectively. While control cooked beef patty contains significantly $(p<0.05)$ more moisture $(59.93 \%)$ than cooked beef patty added with $2 \%$ BRP $(57.40 \%)$. In addition, the cooked beef patty with $2 \%$ BRP contains significantly $(\mathrm{p}<0.05)$ more moisture than 4\% BRP (55.54\%) and 6\% BRP cooked beef patties $(54.92 \%)$. However, there was no significant difference $(p>0.05)$ between $4 \%$ and $6 \%$ BRP cooked beef patty. The carbohydrate content in cooked beef patties was increased proportionally with the levels of BRP incorporation into beef patty formulations. Mean carbohydrate content of BRP-based cooked beef patty significantly differed $(p<0.05)$ from control cooked beef patty. Cooked beef patties with $2 \%, 4 \%$ and $6 \%$ BRP contain $8.71 \%, 11.45 \%$ and $11.78 \%$ of carbohydrate, respectively, which higher than control cooked beef patty $(7.43 \%)$. Cooked beef patty with $2 \%$ BRP showed significantly $(\mathrm{p}<0.05)$ higher carbohydrate content than control cooked beef patty. However, there was no significant difference ( $p>0.05)$ between $4 \%$ and $6 \%$ BRP cooked beef patties in term of carbohydrate content. Nevertheless, the $6 \%$ BRP cooked beef patty had significantly $(\mathrm{p}<0.05)$ greater $\mathrm{CHO}$ content compared to control cooked beef patty. The addition of BRP in beef patty formulations did not affect the calorie content of cooked beef patties. The $2 \%$ BRP cooked beef patty produced slightly lower calorie content $(588 \mathrm{kcal} / 100 \mathrm{~g})$ than control cooked beef patty $(592 \mathrm{kcal} / 100 \mathrm{~g})$ which was not significant $(\mathrm{p}>0.05)$. The $4 \%$ BRP cooked beef patty contains $584 \mathrm{kcal} / 100 \mathrm{~g}$ which was also not significantly different $(\mathrm{p}>0.05)$ with control cooked beef patty. The 4\% BRP cooked beef patty also did not differ significantly $(\mathrm{p}>0.05)$ with $6 \%$ BRP cooked beef patty.

\subsection{Cooking characteristics of cooked beef patties}

Figure 5 shows the physical characteristics of cooked beef patties formulations with brown rice powder (Figure $3)$. The result of potato starch substitution with BRP indicated that the percentage of moisture retention of cooked beef patties was ranged from $43.38 \%$ to $47.66 \%$. Moisture retention in control, 2\%, 4\% and $6 \%$ formulations of cooked beef patty indicated that $47.66 \%$, $44.83 \%, 43.38 \%$ and $44.19 \%$ subsequently. The result of fat retention indicated that the $6 \%$ brown rice powder formulation showed the highest fat retention $(74.64 \%)$ with significant difference $(\mathrm{p}<0.05)$ followed by control cooked beef patty $(72.89 \%)$. Furthermore, the fat retention of $2 \%$ BRP cooked beef patty formulation showed slightly lower (71.47\%) than control cooked beef patty, but no significant difference $(p>0.05)$. On the other hands, fat retention of 4\% BRP cooked beef patty significantly $(\mathrm{p}<0.05)$ gave lower values $(69.21 \%)$ compared with $6 \%$ BRP cooked beef patty. Addition of the highest to the lowest percentage of brown rice powder in beef patty formulation resulted in the decrement of diameter reduction percentage of cooked beef patties consequently. The result of $6 \%$ BRP formulation showed that significantly $(p<0.05)$ the lowest percentage $(13.33 \%)$ of diameter reduction followed by $4 \%$ and $2 \%$ cooked beef patty $(15.00 \%$, $18.00 \%)$. Percentage of diameter reduction in control $(16.67 \%)$ and $4 \%$ BRP cooked beef patty $(15.00 \%)$ was significantly $(\mathrm{p}<0.05)$ lesser than $2 \%$ BRP cooked beef patty. The result of the cooking yield of formulation of brown rice powder showed that slightly changes in the cooking yield of beef patties. The result demonstrated that the cooking yield of cooked beef patty added with $6 \%$ BRP was the highest compared to other patties. However, the increment was not significant $(p>0.05)$ among all formulations and control cooked beef patty.

\subsection{Sensory acceptability of cooked beef patties}

Sensory evaluation scores for cooked beef patties formulated with different levels of brown rice powder formulation were shown in Table 2. Generally, the scores of all attributes were decreased with the levels of brown rice powder (BRP) added in the beef patty (Figure 3 ). The result of colour attribute showed that cooked beef patty formulated with $2 \%$ BRP was found to be comparable with control cooked beef patty since, there was no significant difference $(p>0.05)$ whereby mean scores received by control and 2\% BRP cooked beef patty was $4.98 \%$. in addition, the result of colour attribute in 4\% BRP cooked beef patty showed significantly $(\mathrm{p}<0.05)$ lower score than control cooked beef patty which was $4.60 \%$, following that the $6 \%$ BRP cooked beef patty likewise had mean score significantly $(\mathrm{p}<0.05)$ lower than control cooked beef patty with $4.43 \%$. The result of textural attribute indicated that the control showed the highest textural attribute score. However, the $6 \%$ BRP cooked beef patty received significantly $(p<0.05)$ lowest score in the textural attribute $(3.95 \%)$. In addition, both cooked beef patty formulated with $2 \%$ and $4 \%$ BRP recorded as a lower textural score than control cooked beef patty $(4.92 \%)$ with scores of $4.78 \%$ and $4.57 \%$, respectively. But there was no significant difference $(\mathrm{p}>0.05)$ between these two formulations with control cooked beef patty. The result of juiciness attribute in both of high percentage of brown rice powder formulation ( $4 \%$ and $6 \%$ ) BRP cooked beef patties showed significantly $(\mathrm{p}<0.05)$ lower score, with $3.82 \%$ and $3.50 \%$, respectively, compared with control cooked beef patty $(5.17 \%)$. The formulation of cooked beef patty added with $2 \%$ BRP $(4.63 \%)$ indicated that significantly $(p<0.05)$ lower score of juiciness compared with control cooked beef patty. The score for flavour attribute decreased with high addition of brown rice 
powder in beef patty formulation. The $6 \%$ brown rice powder cooked beef patty significantly $(\mathrm{p}<0.05)$ recorded the lowest flavour score compared to control. Cooked beef patty formulated with $2 \%$ and $4 \%$ BRP significantly $(p<0.05)$ received less flavour score compared with control. For overall acceptance, the control and 2\% BRP cooked beef patty received scores of $5.25 \%$ and $5.03 \%$, respectively without any significant different $(\mathrm{p}>0.05)$. Cooked beef patty containing $4 \%$ BRP scored $4.38 \%$ for overall acceptance which significantly $(p<0.05)$ lower than control and cooked beef patty formulation with $2 \%$ BRP. Overall acceptance of flavour for cooked beef patty containing 6\% BRP recorded $4.13 \%$ score which slightly lower than cooked beef patty containing 4\% BRP but there was no significant different $(\mathrm{p}>0.05)$.

\section{Discussion}

\subsection{Nutritional composition of beef patties}

The data obtain of brown rice powder incorporated into process meat products in the present study revealed that among all nutritional composition, both protein and carbohydrate content were detected higher in both raw and cooked beef patty. These findings were similar to the study done by the previous researcher who reported that brown rice had high protein $(4.88 \mathrm{~g}), \mathrm{CHO}(49.7 \mathrm{~g})$ and dietary fibre content (Jiang et al., 2008). The significant increase in the protein content with 6\% BRP incorporation was in line with the findings from other studies (Babu et al., 2009). Furthermore, according to Alice and Wan Rosli (2015), the addition of 6\% cornsilk powder in beef patties significantly recorded the highest protein content in both raw and cooked beef patties as compared to the control. This result value that detected may due to the moderate amount of protein $(12.96 \%)$ existing originally in dried cornsilk. Consequently, the similar result was reported by Rosli and Anis (2012) that the formulation of young corn powder (YCP) $(10,20 \%$ and $30 \%$ ) with cookies which is result showed that significantly increased in the protein content. In addition, Ahmad et al. (2015) also showed that Kuih Baulu formulated with stabilized rice bran $(10 \%, 20 \%, 30 \%$ and $40 \%$ ) significantly increased the protein content (Sharif et al., 2009). The result of fat content in the current study was in line with the finding from other research that showed the fibre-based formulation products effected to reduce fat content (Rosli et al., 2011). In addition, a similar report was stated by Wan Rosli et al. (2011) which is indicated that the highest amount of $(6 \%)$ cornsilk powder in both raw and cooked beef patties showed the lowest fat percentage compared with other treatment. Due to the previous reports, the addition of dietary fibre to bakery products will improve their nutritional quality since it makes possible to decrease the fat content, by using dietary fibre as substitutive of fat without loss of quality (Martin, 1999). Furthermore, Verma and Banerjee (Verma and Banerjee, 2010), showed that the oat fibre to be suitable fat replacement in ground beef and pork sausage products due to its ability to retain water and emulate particle definition in ground meat in terms of both colour and texture. Due to the previous report, researcher attempt to develop low salt, low fat and high fibre functional chicken nuggets, with incorporated various fibre sources such as pea hull flour, gram hull flour, apple pulp and bottle gourd in different combinations at 10\% level (Verma et al., 2009). The result of the moisture content in the current study was opposed with the finding documented by the previous report (Ahmad et al., 2015), which is the moisture content of Kuih Baulu increased proportionally with the addition of stabilized rice bran as compared to the control $(0 \%)$. In addition, earlier researcher also reported that significant increment in the moisture content with the addition of young corn powder (YCP) in the bread (Lim and Wan Rosli, 2013), cheonnyuncho powder in the sponge cakes (Kim et al., 2012), green tea in sponge cake (Lu et al., 2010) and the nutrim oat bran in shortened cake (Dadkhah et al., 2012). The result of ash content showed significant difference between both raw and cooked beef patties incorporated with $4 \%$ and $6 \%$ of BRP compared to the control $(0 \%)$. This finding was in line with the previous study conducted by (Rosli et al., 2011) which was indicated the significantly increased proportionally in ash content with addition of cornsilk powder. (Ahmad et al., 2015), also reported that the ash content in Kuih Baulu incorporated with stabilized rice bran was significantly higher than the control (Ahmad et al., 2015). Besides that, this finding is also in line with significantly increased in ash content of cookies formulated with young corn powder (YCP) (Rosli and Anis, 2012). However, ash content represents the mineral content of certain food or food product. Thus, the present findings indicated that the incorporation of brown rice powder has a significant effect on the mineral content of beef patties formulation. Furthermore, caloric content in cooked beef patties had no significant difference among all the treatment and the control $(0 \%)$. Hence, the present findings indicated that the incorporation of brown rice powder does not have a significant effect on the total energy of cooked beef patties although there was a very slight increase in the calorie content of cooked beef patties added with $6 \%$ of brown rice powder as compared to the control $(0 \%)$.

\subsection{Cooking characteristics of cooked beef patties}

In the current study, the result of physical characteristics of beef patties formulation showed the 
level fluctuation in some characteristics (Figure 6). The result of cooking yield indicated that the yield of cooking beef patties was increased in line with level of brown rice powder. The result of cooking yield in the current study was in line with the yield of cooking beef patty formulated with cornsilk powder as reported by Wan Rosli et al. (2011). This is an important finding in the understanding of the presence of dietary fiber in formulation beef patty that effected to keep moisture and fat in the matrix. The result of the highest beef patty formulation showed the lowest percentage in diameter reduction compared with other treatment. This analysis found evidence for the binding and stabilizing property of brown rice powder fibre, which held the meat particle together and resisted changes in the shape of the product. However, the present result of percentage in diameter reduction of beef patty formulation was in contrast with the previous report of beef patties formulation with cornsilk powder (Rosli et al., 2011). In addition, the similar result was reported in low-fat patty formulation with oat's soluble fibre which showed no significant in diameter reduction of low-fat patty containing oat's soluble fibre and control (Pinero et al., 2008). Fat retention of beef patty formulated with a higher percentage of brown rice powder showed the highest amount compared to the control sample. This present result showed the contrast result of beef patty formulation with cornsilk conducted by Wan Rosli et al. (2011). In addition, a similar result of ground buffalo meat patties on the physico-chemical and sensory characteristics of low-fat levels was reported by the previous researcher (Suman and Sharma, 2003). However, potato starch substitution with brown rice powder resulted in the decrement of moisture retention of beef patties. This result was incompatible with the character of dietary fibre that has the ability to keep moisture and fat in the patty matrix. Overall, it is clear that this result also contrasted with the study of moisture retention in beef patties formulated with cornsilk powder (Rosli et al., 2011).

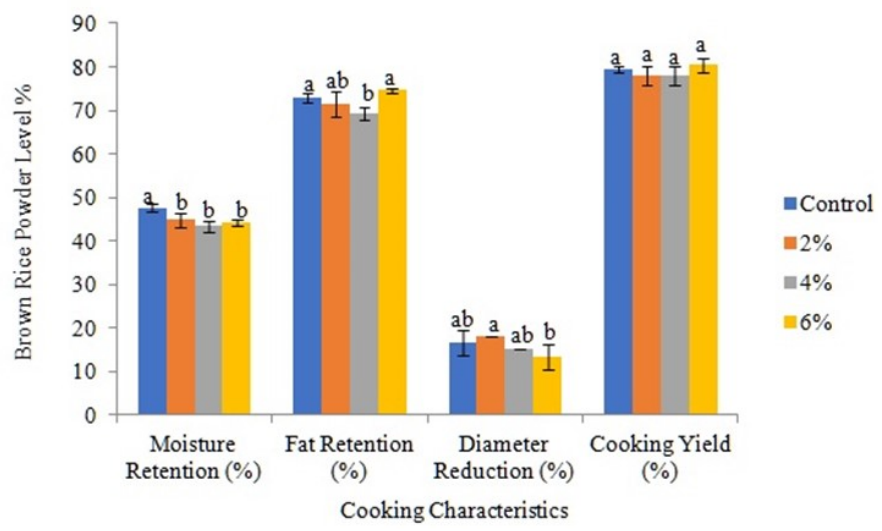

Figure 6. Cooking characteristics of beef patty incorporated with BRP.

a-b Mean values within the same column bearing different superscripts differ significantly $(\mathrm{P}<0.05)$.

\subsection{Sensory acceptability of cooked beef patties}

Among all the sensory results control beef patty $(0 \%)$ of brown rice powder had the highest scores for all of the sensory attributes. The result reported by the previous researcher indicated among of PSC-based patty treatments, patties containing 25\% PSC had the highest scores for all sensory attributed except for juiciness attribute (Wan Rosli, 2012). On the other hand, other finding was in contradictory as result showed that beef patty formulated with oat's fibre indicated the significantly juicier than the control, which could be attributed to the increased moisture retention of the product during cooking (Pinero et al., 2008). The result showed that colour attribute was increased in darkness in line with the level of BRP used in the patty formulation. However, the score for the colour attribute was obtained in the control beef patties $(0 \%)$ was not significantly different with beef patties added with $2 \%$ of BRP. The previous researcher has reported that the rice bran present in the brown rice powder which has light tan colour, may contribute to the colour of BRP-incorporated beef patties (Luh, 1991). In addition, due to previous reported, the bran in the rice flour was described as having a sweet, slightly toasted, nutty flavor, although, the compounds responsible for the characteristic flavor in rice bran are still unknown(Verma et al., 2009). The result of texture of beef patties was in line with previous researchers whose reported that the dilution effect of nonmeat ingredients in meat protein systems primarily accounted for soft texture (Tsai et al., 1998). Thus, the addition of rice bran could improve the texture of beef patties while the highest addition of BRP in beef patty showed less favoured than others. This maybe happened due to the error of the processing period (Hammond, 1994). To summarize, consumers were preferred beef patties in the lowest level (control (without BRP) and 2\% BRP) beef patties as the score were 5.25\% and 5.03\%, respectively. However, there were not significantly different. Besides that, consumers moderately accept beef patties formulated with both $4 \%$ and $6 \%$ of BRP. This finding was similar to the previous study where the addition of BRP by-products such as rice bran was not acceptable at the levels above $30 \%$ in kuih baulu (Ahmad et al., 2015).

\section{Conclusion}

Incorporation of different percentage of brown rice powder in beef patties resulted in the improvement and reduction percentage of protein and fat content consequently. On the other hand, moisture content decreased while the percentage of BRP was increased. Furthermore, increasing the percentage of BPR $(6 \%)$ in beef patties formulation has resulted in the lowest 
diameter reduction compared to other formulation. In the sensory evaluation, there were no differences recorded in all sensory attributes of BRP-based patties as perceived by panellists. This novel food item which being incorporated in beef patties provides informative knowledge about the production of healthy meat patties due to the growing interest among consumers towards health concern and reduction of the formulation cost without affecting sensory evaluation attributes.

\section{Conflict of Interest}

The authors declare that they have no conflicts of interest.

\section{Acknowledgments}

The authors acknowledge Universiti Sains Malaysia for post-doctoral fellowship scheme and the Ministry of Education and Universiti Sains Malaysia in providing funding and facilities for the smooth running of this study.

\section{References}

Ahmad, R., Khalid, K.H., Ali, H.M., Abdullah, S.N.S. and Ahmad, M.Z. (2015). Nutritional composition and sensory properties of kuih baulu incorporated with stabilized rice bran. Journal of Tropical Agriculture and Food Science, 39, 1-9.

Alice, C.L.V. and Wan Rosli, W.I. (2015) Effects of brown rice powder addition on nutritional composition and acceptability of two selected Malaysian traditional rice-based local kuih, International Food Research Journal, 22(3), 11241131.

Babu, P.D., Subhasree, R.S., Bhakyaraj, R. and Vidhyalakshmi, R. (2009). Brown rice-beyond the colour reviving a lost health food-a review. American-Eurasian Journal of Agronomy, 2(2), 6772.

Dadkhah, A., Hashemiravan, M. and Seyedain-Ardebili, M. (2012). Effect of shortening replacement with nutrim oat bran on chemical and physical properties of shortened cakes. Annals of Biological Research, 3 (6), 2682-2687.

El-Magoli, S.B., Laroia, S. and Hansen, P.M.T. (1996) Flavor and texture characteristics of low-fat ground beef patties formulated with whey protein concentrate. Meat Science, 42(2), 179-193. https:// doi.org/10.1016/0309-1740(95)00032-1

Hammond, N. (1994). Functional and nutritional characteristics of rice bran extracts. Cereal Foods World, 39, 752-754
Jiang, S.L., Wu, J.G., Thang, N.B., Feng, Y., Yang, X.E. and Shi, C.H. (2008). Genotypic variation of mineral elements contents in rice (Oryza sativa L.)'. European Food Research and Technology, 228(1), 115. https://doi.org/10.1007/s00217-008-0914-y

Joint FAO/WHO Expert Committee on Food Additives. (2007). Evaluation of certain food additives and contaminants: sixty-eighth report of the Joint FAO/ WHO Expert Committee on Food Additives. Geneva: WHO Press

Kim, J.H., Lee, H. J., Lee, H.-S., Lim, E.-J., Imm, J.-Y. and Suh, H.J. (2012). Physical and sensory characteristics of fibre-enriched sponge cakes made with Opuntia humifusa. LWT-Food Science and Technology, 47(2), 478-484. https://doi.org/10.1016/ j.lwt.2012.02.011

Lim, J.Y. and Wan Rosli, W.I. (2013). The ability of Zea mays ears (Young Corn) powder in enhancing nutritional composition and changing textural properties and sensory acceptability of yeast bread. International Food Research Journal, 20(2), 799804.

Lu, T.-M., Lee, C.-C., Mau, J.-L. and Lin, S.-D. (2010) Quality and antioxidant property of green tea sponge cake. Food Chemistry, 119(3), 1090-1095. https:// doi.org/10.1016/j.foodchem.2009.08.015

Luh, B.S. (1991). Rice, Volume 2: Utilization. USA: Springer Science and Business Media.

Martin, K. (1999). Replacing fat, retaining taste. Food Enginery International, 24(3), 57-58.

Musa, A.S.N., Umar, M. and Ismail, M. (2011) 'Physicochemical properties of germinated brown rice (Oryza sativa L.) starch', African Journal of Biotechnology, 10(33), 6281-6291.

Pinero, M.P., Parra, K., Huerta-Leidenz, N., De Moreno, L.A., Ferrer, M., Araujo, S. and Barboza, Y. (2008) Effect of oat's soluble fibre ( $\beta$-glucan) as a fat replacer on physical, chemical, microbiological and sensory properties of low-fat beef patties. Meat science, 80(3), 675-680. https://doi.org/10.1016/ j.meatsci.2008.03.006

Rosli, W.I.W. and Anis, J. C. (2012). The potential of Zea mays ears and it extracts as an alternative food nutritive ingredients. APCBEE Procedia, 2, 141147. https://doi.org/10.1016/j.apcbee.2012.06.026

Rosli, W., Nurhanan, A.R., Solihah, M.A. and Mohsin, S.S.J. (2011). Cornsilk improves nutrient content and physical characteristics of beef patties. Sains Malaysiana, 40(2), 155-161.

Sharif, M.K., Butt, M.S., Anjum, F.M. and Nawaz, H. (2009). Preparation of fiber and mineral enriched defatted rice bran supplemented cookies. Pakistan 
Journal of Nutrition, 8(5), 571-577. https:// doi.org/10.3923/pjn.2009.571.577

Suman, S.P. and Sharma, B.D. (2003). Effect of grind size and fat levels on the physico-chemical and sensory characteristics of low-fat ground buffalo meat patties. Meat Science, 65(3), 973-976. https:// doi.org/10.1016/S0309-1740(02)00313-3

Tsai, S., Unklesbay, N., Unklesbay, K. and Clarke, A. (1998). Textural Properties of Restructured Beef Products with Five Binders At Four Isothermal Temperatures. Journal of Food Quality, 21(5), 397$410 . \quad$ https://doi.org/10.1111/j.17454557.1998.tb00531.x

Verma, A.K. and Banerjee, R. (2010). Dietary fibre as functional ingredient in meat products: a novel approach for healthy living - a review. Journal of Food Science and Technology, 47(3), 247-257. https://doi.org/10.1007/s13197-010-0039-8

Verma, A.K., Sharma, B.D. and Banerjee, R. (2009). Quality characteristics and storage stability of low fat functional chicken nuggets. Fleischwirtsch International, 24, 52-57.

Wan Rosli, W.I. (2012). Effect on the addition of Pleurotus sajor-caju (PSC) on physical and sensorial properties of beef patty. International Food Research Journal, 19(3), 993-999.

Zhang, G., Malik, V.S., Pan, A., Kumar, S., Holmes, M.D., Spiegelman, D., Lin, X. and Hu, F.B. (2010) Substituting brown rice for white rice to lower diabetes risk: a focus-group study in Chinese adults. Journal of the American Dietetic Association, 110 (8), 1216-1221. https://doi.org/10.1016/ j.jada.2010.05.004 